\title{
Structural Behaviour Benefits of a Hybrid Steel-bamboo Emergency House
}

\author{
Roberto Alonso González Lezcano ${ }^{1, *}$, Juan Manuel Ros García ${ }^{1}$ \\ and Susana Hormigos Jiménez ${ }^{2}$ \\ ${ }^{1}$ Escuela Politécnica Superior, Universidad CEU San Pablo, \\ Montepríncipe Campus, 28668, Boadilla Del Monte, Madrid, Spain \\ ${ }^{2}$ Architectonic Constructions, Physics Department, Universitat de les Illes Balears, \\ Ctra. Valldemossa, km 7.5, E-07122, Palma (Majorca), Balearic Islands, Spain \\ E-mail:rgonzalezcano@ceu.es; jmros.eps@ceu.es; susana.hormigos@uib.es \\ ${ }^{*}$ Corresponding Author
}

Received 16 April 2018; Accepted 07 October 2018;

Publication 29 October 2018

\begin{abstract}
According to the need of emergency houses all around the world, the development of a prototype (low cost and high strength structure) which could be placed anywhere becomes essential. This placement could be in susceptible areas to earthquakes, floods or armed conflicts. It has been studied the behaviour of a steel-bamboo hybrid structure compared with a steelaluminium hybrid one (in terms of strength). Finite elements software has been used to simulate both models. It has been obtained the maximum quantity of bamboo which can be placed in the prototype achieving the optimum design. As far as strength is concerned, steel-aluminium is better than steel-bamboo; even though, it exists minimum difference $(9.16 \%)$, which is despicable considering the advantages of bamboo. When using bamboo as alternative material, displacement varies because of the density of the elements. The structural model becomes lighter and, according to that, it supposes an increase in the displacement (about $0.4 \mathrm{~mm}$ ).
\end{abstract}

Keywords: Sustainability, steel-bamboo hybrid structure, emergency house, green building, numerical simulations.

Journal of Green Engineering, Vol. 8_3, 339-358. River Publishers

doi: 10.13052 jge 1904-4720.837

This is an Open Access publication. (c) 2018 the Author(s). All rights reserved. 


\section{Introduction}

To solve the problem of economic living, the use of bamboo as construction material has a significant potential as it is a low-cost material and easily renewable.

One of the key factors which contribute to those characteristics is the cultivation of the plant as bamboo is often planted through cuttings, not through seeds. This is because most bamboos flower rarely (once in a period varying from 15 to over 100 years) and it is not possible to wait so long. The original culm can be cut into pieces and all young sprouts replanted. Other methods could be: offset method, rhizome, layering, macro proliferation and tissue culture [1].

According to Liese $(1987,1992)$ bamboo is the fastest growing plant currently known. In many countries where it is harvested, it is used as structural material. It takes between 3 and 8 years for bamboo to reach its maximum strength properties [2].

Bamboo cultivation is developed in tropical and subtropical areas with wild climates so the activity remains confined in a range above $45^{\circ}$ latitude North and South until reaching an altitude of 3500 metres [3, 4]. This area is shown in Figure 1 and it is also where most countries with thousands of refugees (because of armed conflicts or natural disasters) are located. Thus, bamboo represents an important resource available for the populations, in case of disaster, to build emergency houses.

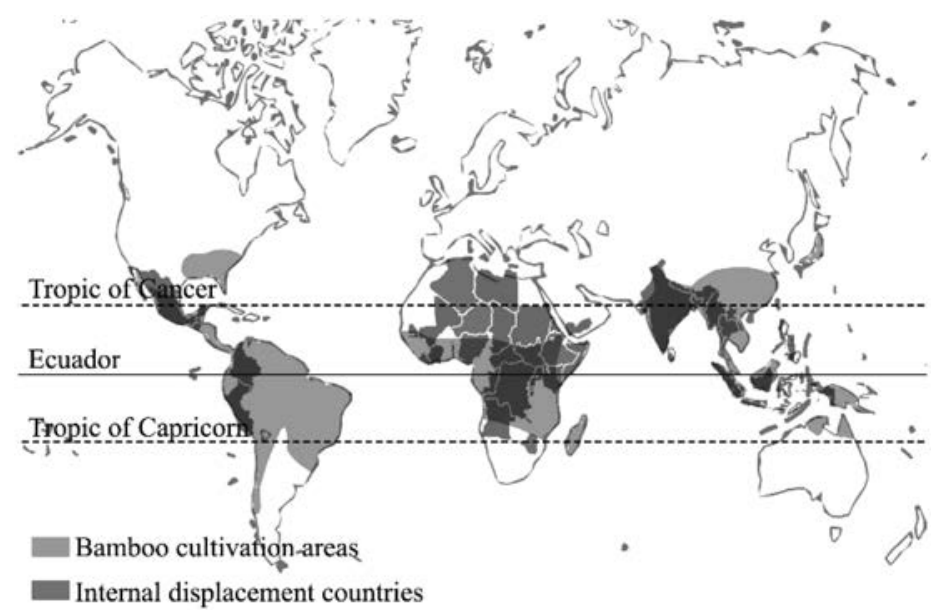

Figure 1 Bamboo cultivation areas (between tropics) and internal displacement countries in the area. 
Considering all those data and knowing that bamboo represents a reliable alternative to expensive and no renewable materials, its use is considered in emergency houses. This type of living must achieve some objectives: low cost, automation and fast assembly and structural security; according to that, bamboo represents one of the best options when building those kinds of houses.

Therefore, it is studied the use, in emergency houses, of a hybrid steelbamboo quadripartite nerves structure, and, to show its benefits, it is compared with another geometry equal structure which is made up by metallic elements: steel and aluminium.

\section{Methodology}

Description of the two case study models.

Two 3D model of an emergency house are created, one of them with a hybrid structure of aluminum and steel and the other one (attending to the behavior of the steel-aluminum hybrid structure) with bamboo and steel, placing bamboo in the areas where less stresses are located. Both have the same spatial geometry.

Finite elements simulation.

Finally, both models are simulated by finite elements software (ABAQUS) and the results obtained are compared.

Bamboo study.

To demonstrate bamboo's safety, it is going to be compared with other materials: steel and concrete. If a comparison between the stress (s) and the possibility of it to occur ( $\mathrm{z}$ ) is shown, it is obtained the following diagram [5]:

The value of "s use" (allowable stress) is considered as the unit to compare the three materials and show the area of stress at failure for bamboo, concrete and steel. Area of stress at failure:

- Steel is a material produced using a very controlled process and hence, bad specimens are very rare; according to that, the area of stress at failure is narrow and steep so failure under stress occurs in a narrow range.

- At the other hand, bamboo is a natural material and the quality varies widely hence, it exists a large distance between the stress at failure and the allowable stress. Considering this fact, it is important to contemplate a high security factor when designing with bamboo. 


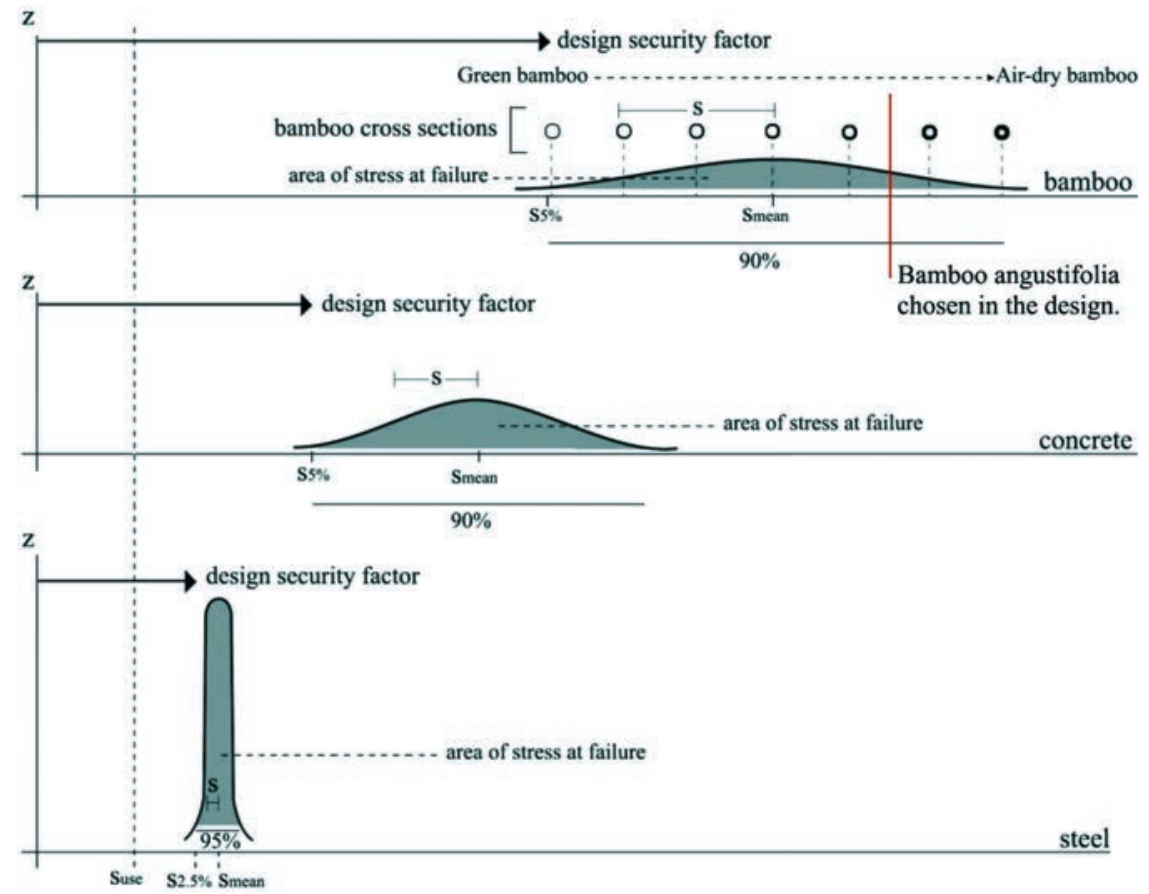

Figure 2 Bamboo, concrete and steel. Comparison between stress and possibility to occur. Based on the figure in page 20 of the Technical Report $\mathrm{N}^{\circ} 20$ of Jules J. A. Janssen (2000), "Designing and Building with Bamboo".

According to the safety, and as the diagram shows, steel is the optimum material (it has the shortest distance between allowable stress and stress at failure). Even though, in case of natural disaster such as earthquake, steel will suffer much damage as the stresses will raise the area of failure, but bamboo structures will remain in good condition. Then, bamboo in one of the best options to design emergency houses as those are going to be located in vulnerable areas which are susceptible to natural disasters.

Mechanical properties of bamboo.

Material per unit volume.

For most bamboos, the density varies, depending on the specie, between $600-800 \mathrm{~kg} / \mathrm{m}^{3}$.

The greater the mass per volume, the heavier the bamboo [6]. 
Table 1 Production energy and density. Comparison between steel, concrete and bamboo [7]

\begin{tabular}{lccccc}
\hline Material & $\begin{array}{c}\text { Energy/ } \\
\text { Production } \\
(\mathrm{MJ} / \mathrm{kg})\end{array}$ & $\begin{array}{c}\text { Density } \\
\left(\mathrm{kg} / \mathrm{m}^{3}\right)\end{array}$ & $\begin{array}{c}\text { Energy/ } \\
\text { Production } \\
\left(\mathrm{MJ} / \mathrm{m}^{3}\right)\end{array}$ & $\begin{array}{c}\text { Fatigue } \\
\left(\mathrm{kN} / \mathrm{cm}^{2}\right)\end{array}$ & $\begin{array}{c}\text { Energy Per } \\
\text { Unit Volume } \\
\left(\mathrm{MJ} / \mathrm{m}^{3}\right)\end{array}$ \\
\hline Steel & 30 & 7800 & 234000 & 1.6 & 150000 \\
\hline Concrete & 0.8 & 2400 & 1920 & 0.08 & 24000 \\
\hline Bamboo & 0.5 & 600 & 300 & 0.1 & 3000 \\
\hline
\end{tabular}

This property is important as it could give some rules; for example, the bending stress at failure $\left(\mathrm{N} / \mathrm{mm}^{2}\right)$ can be estimated as being 0.14 times the mass per volume $\left(\mathrm{kg} / \mathrm{m}^{3}\right)$.

Relation between inertia moment and cross section area.

○ $\mathrm{I}=\left(\pi \times\left(\mathrm{D}^{4}-\mathrm{d}^{4}\right)\right) / 64$

$\circ \mathrm{A}=\left(\pi \times\left(\mathrm{D}^{2}-\mathrm{d}^{2}\right)\right) / 4$

$$
\mathrm{I}=0.16 \times \mathrm{A}^{2}
$$

Where:

I, inertia moment.

A, cross section area.

$\mathrm{D}$, external diameter.

$\mathrm{d}$, internal diameter.

E modulus for cellulose and fibre.

E modulus for bamboo must be divided into cellulose and fibre. Cellulose fibres in bamboo act like steel bars reinforcement in concrete providing strength to the structure.

The concentration of fibres goes rising from the internal to the external part of the culm.

- E modulus for cellulose is $70000 \mathrm{~N} / \mathrm{mm}^{2}$ (and about $50 \%$ of the cross section is cellulose).

- E modulus for fibres is $35000 \mathrm{~N} / \mathrm{mm}^{2}$.

Considering that, in most bamboos, the distribution of fibres is concentrated in about $60 \%$ in the exterior of the cross section and $10 \%$ in the interior, the following values for the $\mathrm{E}$ modulus have been took to simulate the model:

- $\mathrm{E}=35000 \cdot(0.6)=21000 \mathrm{~N} / \mathrm{mm}^{2}$ (exterior).

- $\mathrm{E}=35000 \cdot(0.1)=3500 \mathrm{~N} / \mathrm{mm}^{2}$ (interior). 
344 R. A. G. Lezcano et al.

Poisson ratio $=0.3$

Bending

- Bending moment produced by wind loads

$$
\mathrm{M}=0.5 \times \pi \times(\mathrm{L}-\mathrm{z})^{2}
$$

Where:

$\mathrm{M}$, bending moment.

$\mathrm{z}$, height.

$\mathrm{L}$, maximum value of the height.

- Bending vs. shear according to four-point bending test Vaessen et al. 1997.

$$
\mathrm{M}=(\mathrm{F} \times \mathrm{L}) / 3=(\mathrm{s} \times \mathrm{I}) / \mathrm{R}
$$

Where:
$\mathrm{M}$, bending moment.
$\mathrm{F}$, each of the two loads.
$\mathrm{L}$, free span.
$\mathrm{s}$, bending stress.
I, inertia moment.
$\mathrm{R}$, external radius of the culm.

According to the four-point bending test:

$$
\begin{gathered}
\mathrm{t}_{\text {crit }}=(2 \times \mathrm{F}) / \mathrm{A} \\
\mathrm{F}=\left(\mathrm{t}_{\text {crit }} \times \mathrm{A}\right) / 2=\left(\mathrm{t}_{\text {crit }} \times \pi \times \mathrm{t} \times(2 \mathrm{R}-\mathrm{t})\right) / 2
\end{gathered}
$$

$\mathrm{L}_{\text {crit }}$ between bending and shear could be obtained taking the two values of $\mathrm{F}$ as equal:

$$
\mathrm{L}_{\text {crit }}=\left(1.763 \times \mathrm{e}_{\text {crit }} \times \mathrm{ER} \times \mathrm{R}\right) / \mathrm{t}
$$

Where:

$$
\begin{aligned}
& \text { - } \mathrm{e}_{\text {crit }}=3.2 \times 10^{-3} \\
& \text { - } \mathrm{ER}=\mathrm{E} \text { in the exterior } \\
& \text { - } \mathrm{R}=\text { external radius of the bamboo culm }(\mathrm{D} / 2) \\
& \text { - } \mathrm{t}_{\text {crit }}=2.6 \mathrm{~N} / \mathrm{mm}^{2}
\end{aligned}
$$




$$
\mathrm{L}_{\text {crit }}=26 \times D \text { or } L_{\text {crit }}=30 \times D
$$

Comparison of bending properties of bamboo to other common building materials.

The following table indicates that bamboo is stronger in bending than timber, and its strength-to-weight ratio (expressed as MOR/specific gravity) is greater than that of all materials listed except carbon fibre.

Deformation.

$$
\begin{gathered}
\mathrm{f}=\left(5 \times \mathrm{q} \times\left(\mathrm{L}^{4}\right)\right) /(384 \times \mathrm{EI}) \\
\text { or } \\
\mathrm{f}=\left(\mathrm{F} \times\left(\mathrm{L}^{3}\right)\right) /(48 \times \mathrm{EI})
\end{gathered}
$$

Tensile strength.

To prevent the deformation of the trunk, bamboo culms are tensed by nodes, which reduce the tensile strength of the trunk.

Tensile strength in the external area is about 2 or 3 times higher than in the internal one and it decreases in the trunks which are 5-6 years.

Compression strength.

It increases according to the age: the elder the trunk, the higher the compression strength. Because of the effect of height, the top portion of bamboo has the highest compressive stress 9 .

Table 2 Comparison of bending properties of bamboo to other common building materials [8]

\begin{tabular}{lcccc}
\hline $\begin{array}{l}\text { Building } \\
\text { Materials }\end{array}$ & $\begin{array}{c}\text { Specific } \\
\text { Gravity }\end{array}$ & $\begin{array}{c}\text { Modulus of } \\
\text { Elasticity } \\
(\text { MOE) }(\mathrm{GPa})\end{array}$ & $\begin{array}{c}\text { Modulus of } \\
\text { Rupture }(\mathrm{MOR}) \\
(\mathrm{MPa})\end{array}$ & $\begin{array}{c}\text { MOR to } \\
\text { Specific Gravity } \\
\text { Ratio }(\mathrm{MPa})\end{array}$ \\
\hline $\begin{array}{l}\text { Giant timber } \\
\text { bamboo }\end{array}$ & 0.52 & 10.7 & 102.7 & 197.5 \\
\hline $\begin{array}{l}\text { Other } \\
\text { bamboo }\end{array}$ & - & $9.0-20.7$ & $97.9-137.9$ & - \\
\hline $\begin{array}{l}\text { Loblolly } \\
\text { pinc }\end{array}$ & 0.51 & 12.3 & 88 & 172.5 \\
\hline Douglas-fir & 0.45 & 13.6 & 88 & 195.6 \\
\hline Cast iron & 6.97 & 190 & 200 & 28.7 \\
\hline $\begin{array}{l}\text { Aluminum } \\
\text { alloy }\end{array}$ & 2.72 & 69 & 200 & 73.4 \\
\hline $\begin{array}{l}\text { Structural } \\
\text { steel }\end{array}$ & 7.85 & 200 & 400 & 50.9 \\
\hline Carbon fiber & 1.76 & 150.3 & $5,650.00$ & $3,205.10$ \\
\hline
\end{tabular}


Table 3 Strength values for Bamboo Guadua [7]

\begin{tabular}{lc}
\hline Bamboo Specie: Guadua & Characteristic Values in $\mathrm{kN} / \mathrm{cm}^{2}$ \\
\hline Tensile strength & 15.0 \\
Compression strength & 2.7 \\
Bending strength & 10.0 \\
Shear strength & 0.9 \\
\hline
\end{tabular}

Shear strength.

Thin walls bamboos have higher shear strength than the ones with thick ones. This is related to de amount of rigid fibres located in the cross section. Shear strength is $50 \%$ higher in the nodes material than the in-between nodes material.

Material per unit volume compared with mechanical properties, according to bamboo type [7]. Air-dry bamboo:

Green bamboo:

Compression: 0.094

Compression: 0.075

Bending: 0.14

Bending: 0.11

Shear: 0.021

The concentration of fibres in the external part of the culm improves not only the elasticity values, but also the ones for tensile, bending and shear.

Flame resistance.

Because of the amount of silicon acid in bamboo cortex and the high density of the material, bamboo could be classified as a flammable but low-fuel element. Flame resistance depends on the position of the components, as the horizontal ones are not as susceptible to ignition as the vertical or the diagonal ones.

Shear behavior.

Bamboos have good behavior under compression loads, where there are no deformations or breakups in tube walls. Fractures use to occur when bending tests are carried out.

Mechanical behavior of bamboo guadua in comparison with timber [10]. Shear behavior of normal construction timber differs significantly from shear bamboo (guadua) conditions.

In bamboo structures, clefts are driven out of the direction of fibres and critical regions are punished. Energy transfer is delayed by dissemination. The distribution of longitudinal clefts all along the culm is stopped by the strength of nodes (strengths under pressure and shear are given by nodes). Those facts are called as the factors which increases shear strength. 
The energy needed too impact a guadua stem is close to be the same as if the impact hits the node or the internode. Even though, shear conditions in each one are totally different. On one hand, if impact occurs in the node, the culm will break into axial strips; this is the result of the action of any force acting on the vertical strength of fibres. On the other hand, if impact occurs in the internode it will break because of any force acting on the tensile strength of the fibre.

Calculation of allowable stresses [11].

According to the Board of the Cartagena Agreement (Junta del Acuerdo de Cartagena, Quito, Ecuador, 1984), in which the main criteria for the use of wood (timber or bamboo) in construction are established, the following factors should be used when designing with bamboo to calculate the structural behavior:

- Reduction factor according to the quality of the product (QF): this factor must be applied because of the variation in the quality of the product (sometimes bamboo guadua could be cracked or it could have small isolated holes).

- Service and security factor (SF): this factor is applied to achieve a proper structural behavior. Last stresses are divided by this factor thus stresses in service conditions are obtained.

- Reduction factor because of size (RF): shear stress decreases in flexion as cross section increases. The same happens in parallel traction to fibres.

- Time factor (TF): shear stresses decrease when the time of application of loads increases.

- Humidity factor (HF): stresses decrease according to the amount of humidity found in the product. It is critical when the material stands in green state. Thus, the higher the amount of humidity, the higher the stresses.

Considering all those factors, the Board of the Cartagena Agreement indicates the following values:

Table 4 Correction factors to calculate allowable stresses

\begin{tabular}{lccccc}
\hline Stress & QF & SF & RF & TF & HF \\
\hline Perpendicular Compression & 1.00 & 1.00 & 1.60 & 1.00 & 1.00 \\
Parallel Compression & 1.00 & 1.00 & 1.60 & 1.25 & 1.00 \\
Bending & 0.80 & 0.90 & 2.00 & 1.25 & 1.00 \\
Parallel shear & 1.00 & 1.00 & 4.00 & 1.00 & 1.00 \\
\hline
\end{tabular}


Model A: steel and aluminum

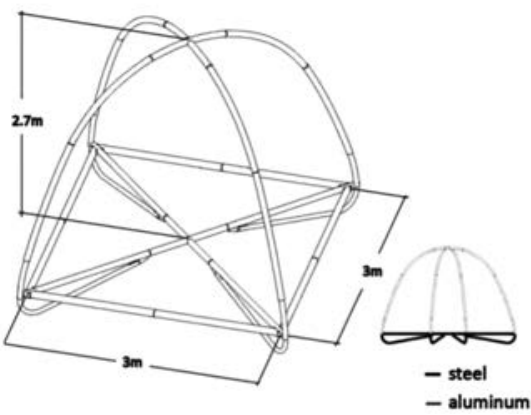

Model B: steel and bamboo

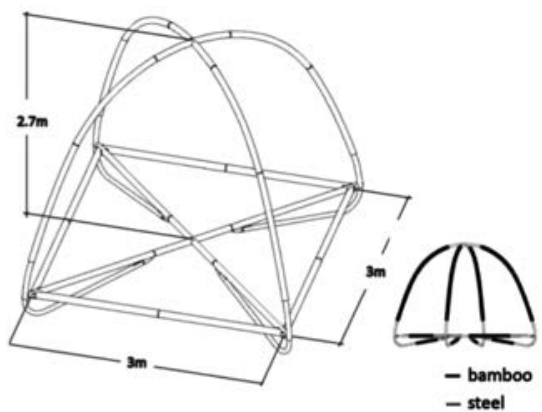

Figure 3 Case study models. Steel and aluminum (model A) and steel and bamboo (model B).

Therefore, the allowable stress (AS) equation is the following one:

$$
\mathrm{AS}=[(\mathrm{QF} \times \mathrm{SF} \times \mathrm{HF}) /(\mathrm{SF} \times \mathrm{TF})] \times \text { last stress }
$$

Description of the two case study models.

To show the results of bamboo behaviour as structural material we have developed a study of two identical models in geometry but different in the construction elements used: one of them, model A, is made up by steel and aluminium elements; meanwhile the other one, model $\mathrm{B}$, is made up by steel and bamboo.

In both models, the same loads have been applied [12]:

Applied Loads and Boundary Conditions:

Snow $20 \mathrm{kp} / \mathrm{m}^{2}$; Roof $3 \mathrm{kp} / \mathrm{m}^{2}$; Wind loads $\alpha=20^{\circ}$; Windward $66 \mathrm{kp} / \mathrm{m}^{2}$; Leeword $-30 \mathrm{kp} / \mathrm{m}^{2}$ Service Loads $2000 \mathrm{kp} / \mathrm{m}^{2}$; Coriolis effect $15 \mathrm{kp} / \mathrm{m}^{2}$; Ballast $1800 \mathrm{kp} / \mathrm{m}^{2}$. Boundary conditions: Supports with clamp fixing.

Finite elements simulation

To study both models, it has been used finite elements method tool because it allows not only representing complex geometries, but it also allows the interaction between the different structural elements in the prototypes. The structure in the software is divided into small interconnected elements by points called nodes. The equations which define the continuum behavior also define the element's one. So, the continuum system with infinite degrees of freedom turns into another one with finite degrees of freedom [13].

The next table shows the problem size (divided by its different factors) faced by the software to calculate and show the behavior of the 3D modelled structure: 
Table 5 Characteristics of the applied mess

\begin{tabular}{ll}
\hline Problem Size & \\
\hline Mesh element & Tetrahedral \\
\hline Geometric order & Quadratic \\
\hline Number of elements & 42747 \\
\hline Number of nodes & 84449 \\
\hline Number of nodes defined by the user & 84449 \\
\hline Total number of variables in the model & 253347 \\
\hline (degrees of freedom plus max no. of any lagrange multiplier & \\
variables include *print, solve $=$ yes to get the actual number.) & \\
\hline
\end{tabular}

There are multiple choices to simulate bamboo behavior by finite elements [14]:

- Modelling of bamboo strip according to its morphology. It is important to consider the physical properties of the material's microstructure. This type of modelling would be useful to determine strength, fracture toughness and fatigue life.

- Laminated composites. The material could be laminated as a composite with several unidirectional continuum layers each with unique mechanical properties. This would be optimum to study the bending behavior of bamboo subjected to different loading types

- 2 Layer composite. This is the simplified version of the laminated composites simulation. Bamboo elements are divided into two layers with different mechanical properties where the outer layer in much stronger than the inner one. This last choice is the one which provides better computational efficiency as the model has been simplified; thus, the numerical analysis would be faster.

According to the characteristic of every modelling option, previously described, 2-layer composite is the one that has been chosen to perform the numerical analysis by finite elements.

Once the analysis method has been chosen, the two models are imported to Abaqus and the materials of its elements are properly defined in the software [15] following the previous mechanical properties study of bamboo, steel and aluminum. Also, the connections (tie) between pieces have had to be specified to achieve the correct results, as well as the loads applied to the structure.

Next, the mesh is defined by using tetrahedral elements in the whole model to show the right behavior as possible. 

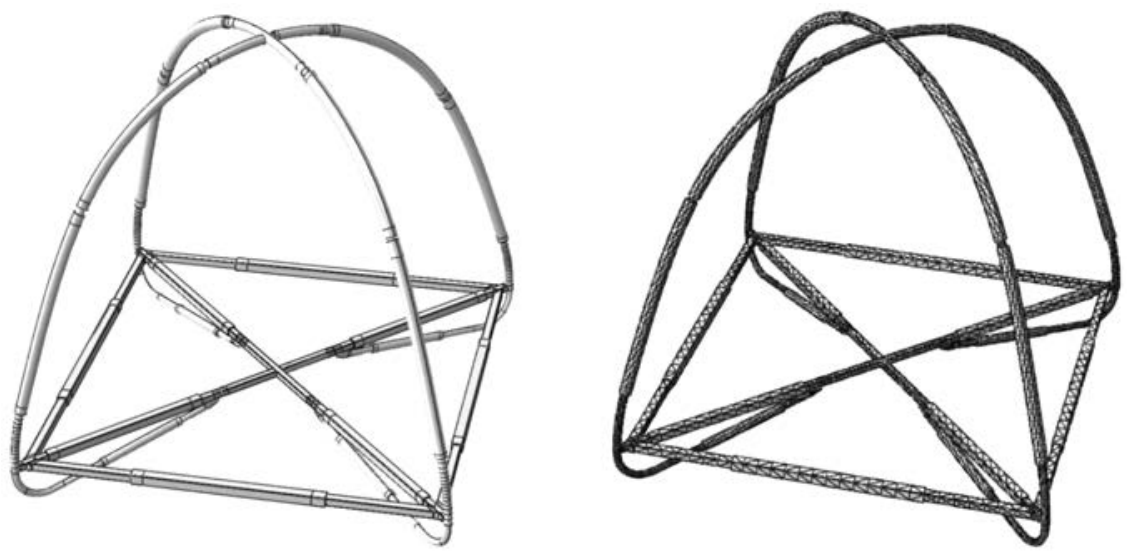

Figure 4 Mesh. Hybrid structure of quadripartite nerves.

\section{Results and Discussions}

The security factor of the model's structure has a value of 1.1, which allows both of them to resist the applied loads.

The areas which suffer low stresses could be seen in both models. This area are located in the middle part of the elements; i.e. every element in the

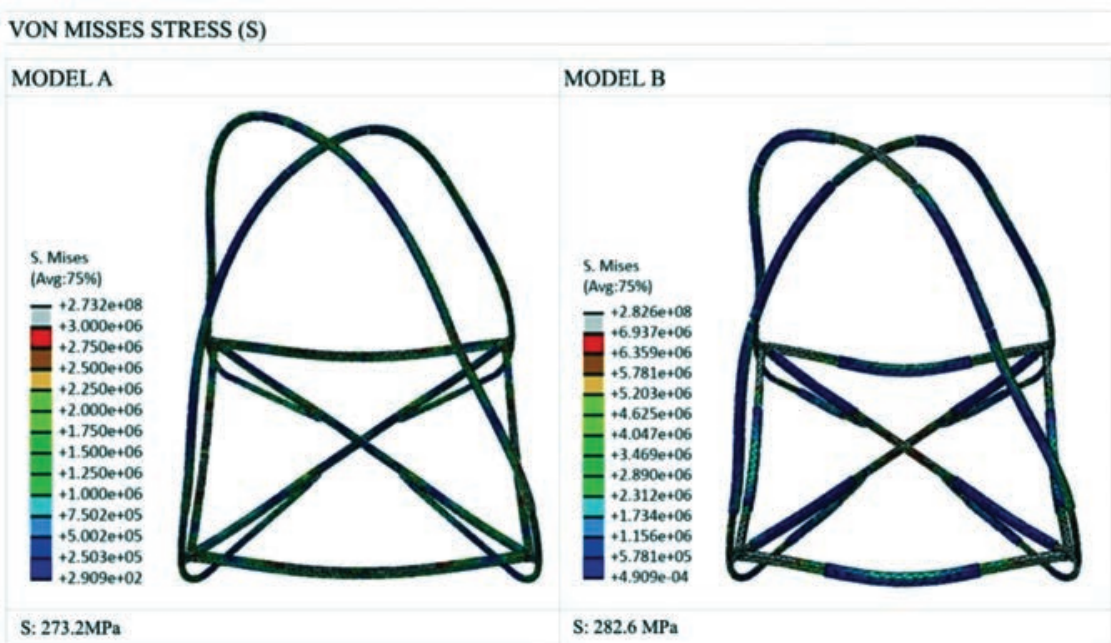

Figure 5 Whole structure. Von Mises stress. 


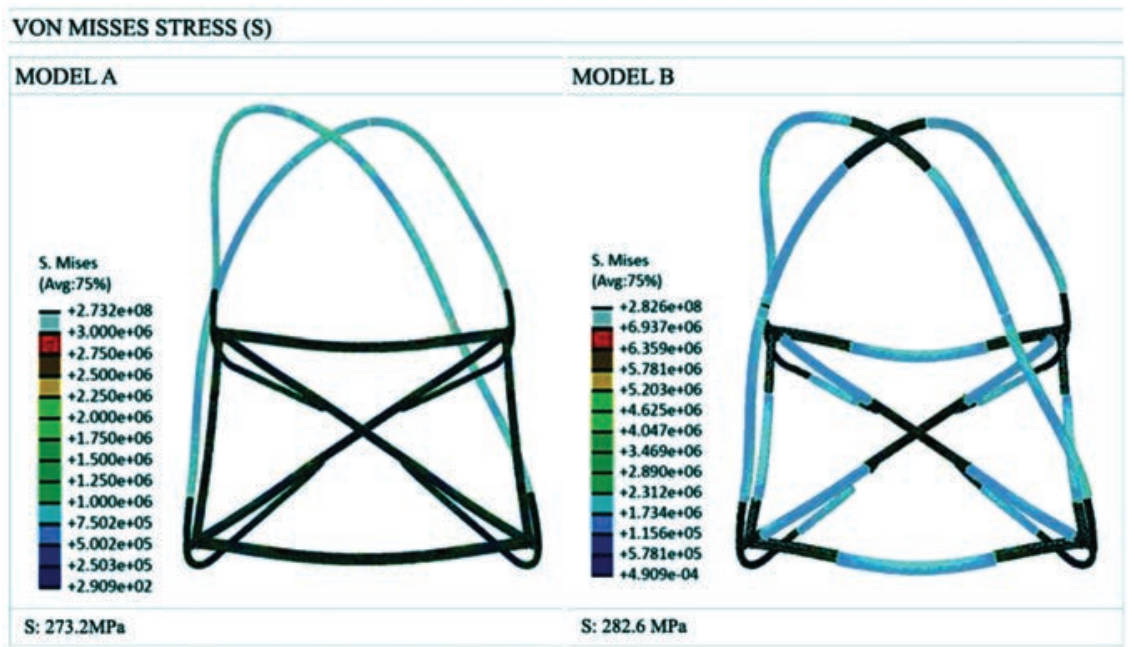

Figure 6 Steel elements. Von Mises stress.

frame, every element in the crossings and in the supports). Those zones are susceptible to be replaced by an alternative material, which could have less strength, less weight and less cost. This is the reason why bamboo has been placed in those areas in model B.

Steel elements absorb higher loads in the hybrid steel-bamboo structure. Next is detailed a comparison of the stresses distribution between both case study models:

As it is seen in Figure 7, steel is the material which absorbs higher loads in both models.

There is a fairer distribution of the loads in model A (steel and aluminum structure) than in model B because in this one the stresses are concentrated in metallic elements, as it is shown next:

We can see that maximum stresses occur, in both models, in the connection between supports and the lower structure. This is the reason why those elements must be made up by steel.

In the next figure can be seen are shown steel elements in model B, which are the ones that absorb the stresses.

Regarding to the behavior of aluminum and bamboo, as it is shown next, we can see that the first one absorbs more stresses that the second one. 


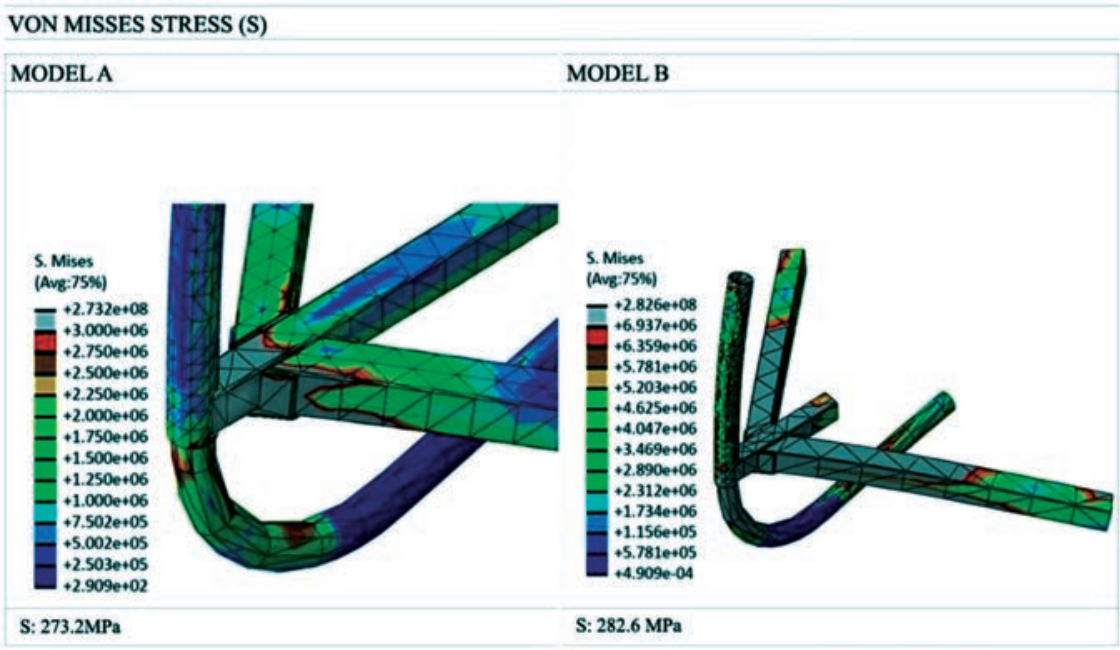

Figure 7 Lower steel elements connection.

\section{VON MISSES STRESS (S)}

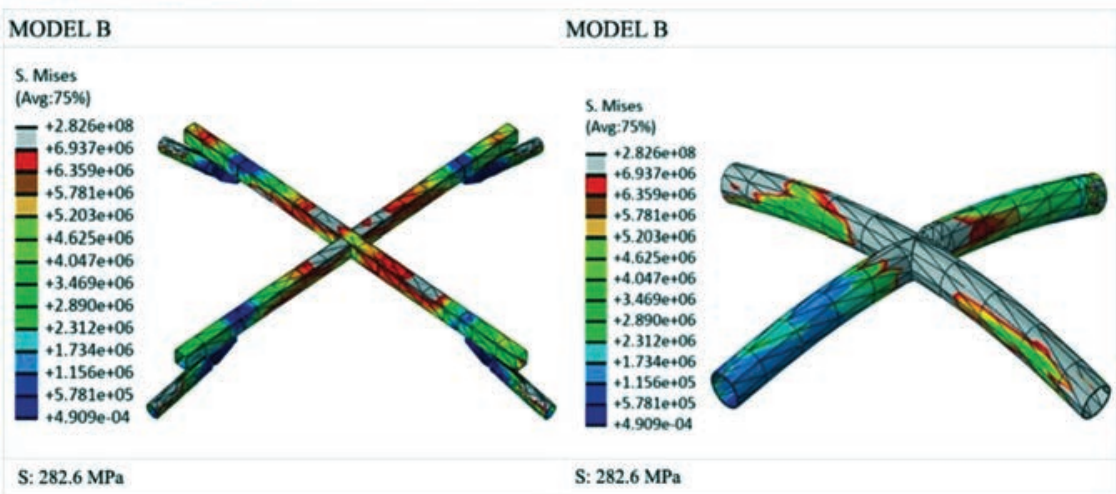

Figure 8 Lower and upper cross elements connection.

We must consider that aluminium is placed all along the upper structure, also in the upper connection. On the other hand, bamboo is used in areas where less stresses are suffered. According to displacement, in model B, when applying bamboo as alternative material it has less density and, because of that, it has a displacement about $0.4 \mathrm{~mm}$ higher than model A. 


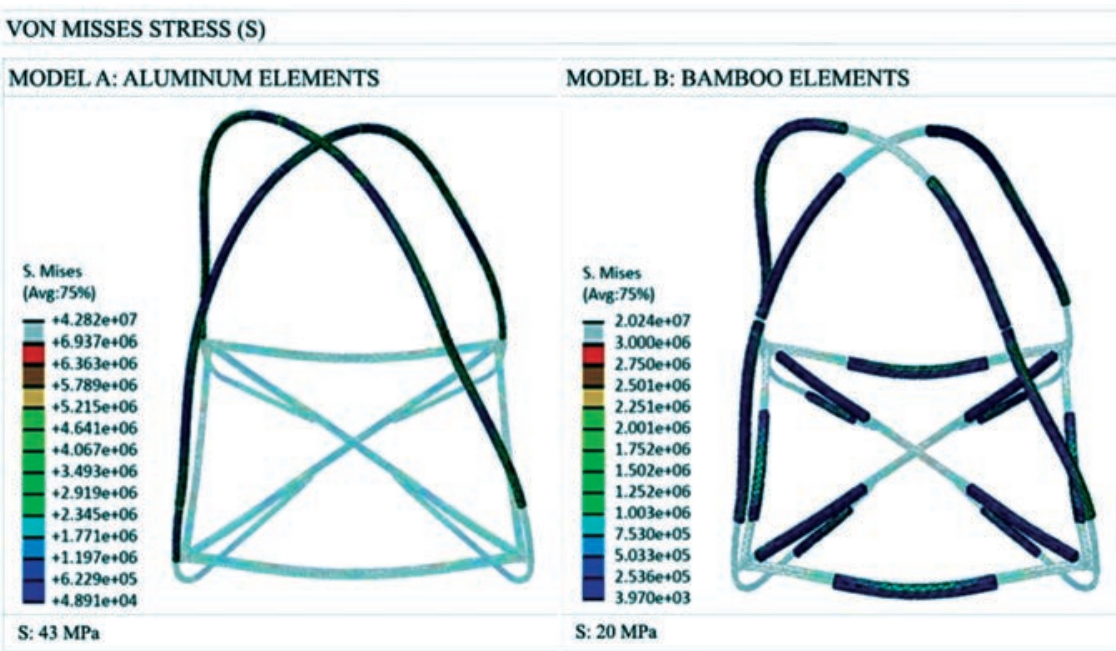

Figure 9 Hybrid structure elements.

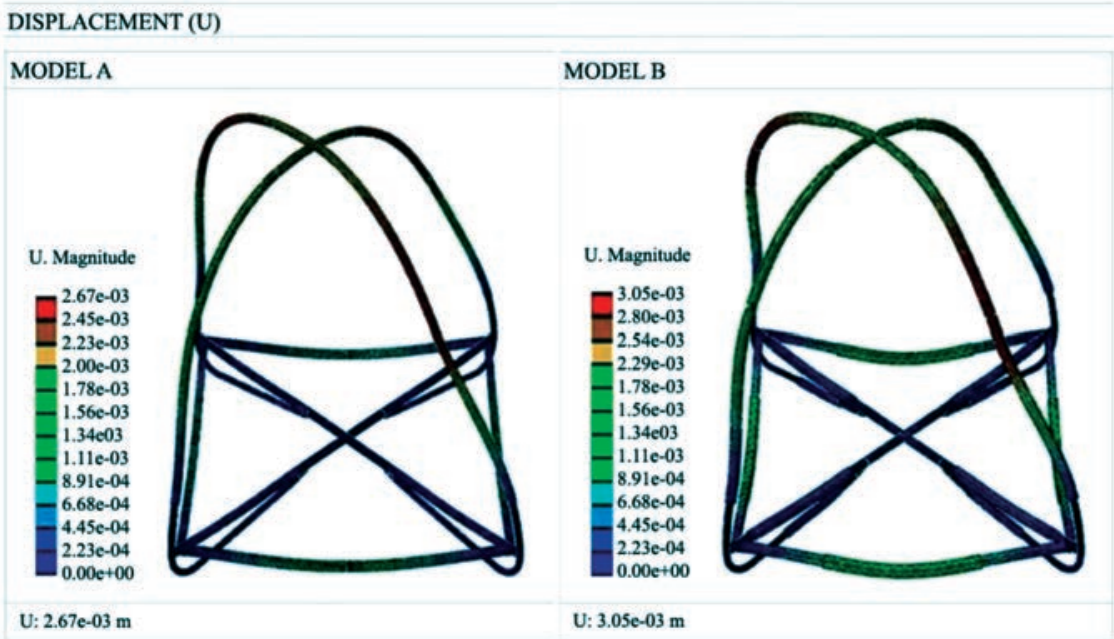

Figure 10 Displacement of Hybrid structure.

\section{Discussions}

According to the study, it can be seen that both models have a similar strength to the loads applied showing a security factor of 1.1 in both prototypes. Nevertheless, the loads absorption is better distributed in model A (steel and aluminium) because in model B are the steel elements which absorb the stresses. 


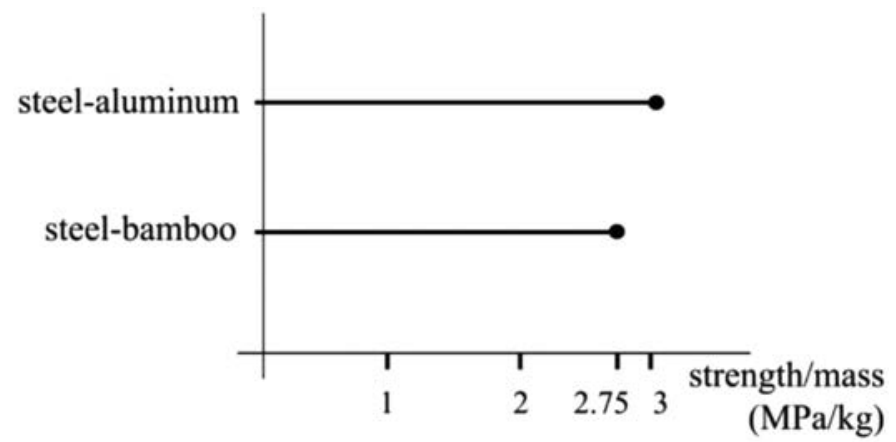

Figure 11 Strength divided by the mass.

The vulnerable areas are located in the connections between the elements, concretely in the connections between the supports and the lower structure. Thus, steel elements must be used.

In response to the question of how much strength does steel-aluminum or steel-bamboo give, the following diagram is elaborated:

The diagram (calculated as the strength divided by the mass) shows that, as far as strength is concerned, steel-aluminum is better than steel-bamboo; even though, it exists minimum difference $(9,16 \%)$, which is despicable considering the advantages of bamboo.

The diagram (Figure 8) shows that model A, made up by metals, when the building is under normal conditions, resists better the stresses; even though, in case of disasters such as earthquakes, model B (steel bamboo) would resist better the stresses according to its mechanical properties (good bending behavior).

When using bamboo as alternative material, displacement varies because of the density of the elements. The structural model becomes lighter and, according to that, it supposes an increase in the displacement (about $0.4 \mathrm{~mm}$ higher than model A).

\section{Conclusions}

For further research, it would be interesting to evaluate the methods of treatment of bamboo guadua such as drying or waterproofing or even preservation methods, in order to determinate if those actions cause an alteration of bamboo mechanical properties, particularly attending to the strength of the material. An investigation into environmental degradation of bamboo would be needed 
to test bamboo utility in long term use [16]. Thus, considering the low cost of bamboo and its benefits due to its mechanical properties bamboo, the material has huge potential obtain a structural use $[17,18]$.

\section{Acknowledgements}

The authors would like to express their sincere gratitude to Rebirth Inhabit Group for the design of the emergency house and the work throughout the course of this study; and to San Pablo CEU Higher Polytechnic School for the guidance and help on the experimental design and assistance.

\section{References}

[1] Jules, J. (2000). Designing and building with bamboo. INBAR Technical Report No. 20. Technical University of Eindhoven, The Netherlands, pp. 10-15.

[2] Mahdavi, M., Clouston, P. L., and Arwade, S. R. (2010). Development of laminated bamboo lumber: review of processing, performance, and economical considerations. Journal of Materials in Civil Engineering, 23(7), 1036-1042.

[3] Fernández, J. P. (2012). ESTUDIO DE FACTIBILIDAD perspectivas para la industrialización de bambú en las regiones de la sierra de per, p. 9.

[4] Galan, Biasin, Cho, Martín (2004). GUADUA (Recurso sostenible). Una mirada desde la Gestión Estratégica de Diseño, p. 7.

[5] Jules, J. (2000). Designing and building with bamboo. INBAR Technical Report. No. 20. Technical University of Eindhoven, The Netherlands, pp. 20.

[6] Lakkad, S. C., and Patel, J. M. (1981). Mechanical properties of bamboo, a natural composite. Fibre Science and Technology, 14(4), 319-322.

[7] Galan, Biasin, Cho, Martín (2004). GUADUA (Recurso sostenible). Una mirada desde la Gestión Estratégica de Diseño, p. 14.

[8] Janssen, J. J. (2000). Designing and building with bamboo International Network for Bamboo and Rattan China, pp. 20.

[9] Li, X. (2004). Physical, chemical, and mechanical properties of bamboo and its utilization potential for fiberboard manufacturing.

[10] González Salcedo. Luis Octavio (2004). "Elementos para la caracterización mecánica de la Guadua Angustifolia Kunth" pp. 6-7. 
[11] González Salcedo. Luis Octavio (2004). "Elementos para la caracterización mecánica de la Guadua Angustifolia Kunth" pp. 9-11.

[12] CEN, E. (2005). 13782: 2005. Temporary structures. Tents. Safety.

[13] García, J. M. R., Lezcano, R. A. G., and Jiménez, S. H. (2014). Evaluación de la influencia del factor de forma de una estructura de nervios cuatripartitos bajo solicitaciones cuasiestáticas. Pensamiento Matemático, 4(2), 75-89.

[14] Ariffin, W. T. W. (2002). Numerical Analysis of Bamboo and Laminated Bamboo Strip Lumber. Research Project.

[15] Bai, X., Lee, A. W., Thompson, L. L., and Rosowsky, D. V. (2007). Finite element analysis of Moso bamboo-reinforced southern pine OSB composite beams. Wood and Fiber Science, 31(4), 403-415.

[16] Lakkad, S. C., and Patel, J. M. (1981). Mechanical properties of bamboo, a natural composite. Fibre science and technology, 14(4), 319-322.

[17] Van der Lugt, P., Van den Dobbelsteen, A. A. J. F., and Janssen, J. J. A. (2006). An environmental, economic and practical assessment of bamboo as a building material for supporting structures. Construction and Building Materials, 20(9), 648-656.

[18] González-Lezcano, R. A., Ros García, J. M., and Hormigos-Jiménez, S. (2015). Numerical simulation of the optimization in the design of a hybrid steel-bamboo rigid floor in a self-supporting structure. El Hombre y la Máquina, (46).

\section{Biographies}

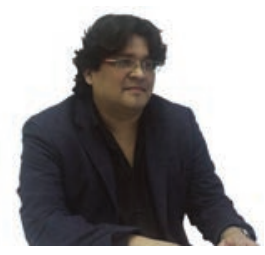

Roberto Alonso González Lezcano, Associate Professor at the Department of Architecture and Design, area of Building Systems, within the Institute of Technology of Universidad CEU San Pablo. Coordinator of the subjects Building Systems as well as Electrical and Lighting systems. Professor Accredited by ACAP in the figures of private university professor and visiting professor. One six-year research period by CNEAI (period 2003-2015). Coordinator of the post-graduate degree of Energy Efficiency and Sustainability in Buildings 
and Coordinator of the Laboratory of Building Systems within Universidad CEU San Pablo. Member of the PhD Program in "Health Science and Technology" and the PhD Program "Composition, History and Techniques pertaining to Architecture and Urbanism". Coordinator of the training activity "Ethical use of scientific documentation" Lecturer of the Master MC2 relevant to Quality in Construction and in the Postgraduate Degree in Overall Management of Buildings and Services at the Universidad Politécnica de Madrid. Coordinator of the Wind Energy Section within the Master's degree in Renewable Energy of the Institute of Technology (Universidad CEU San Pablo).

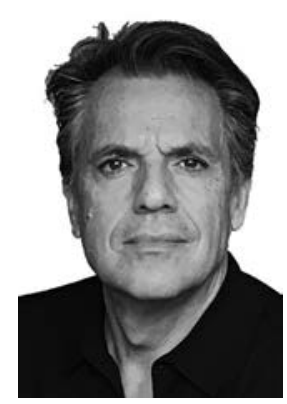

Juan Manuel Ros García, Assistant Professor of Architectural Design, permanent position, Department of Architecture and Design. Institute of Tecnology (E.P.S.) CEU San Pablo University. Degree in Architecture. (B.Sc) Universidad Politécnica de Madrid. Higher Technical School of Architecture of Madrid. Spain with Distinctive Honor. Building Construction and Professional Practice. Principal Researcher Team of REbirth.Inhabit group. National accreditation as a university professor by the ANECA state agency. Two periods of 6 years on research work recognized by the Ministry of Education and Science. Invitations, stays and research collaborations within the framework of international agreements. In the field of specialized architecture: Author and participant in quality publications, exhibitions, conferences and national and international symposiums on architecture in situations of humanitarian crisis, and biohealthy applications. Author of different patents within the field of technology transfer and director of the Architectural Innovation Workshop in the Degree of Architecture. Winner of two calls (2015-2017) for the Angel Herrera research awards. 


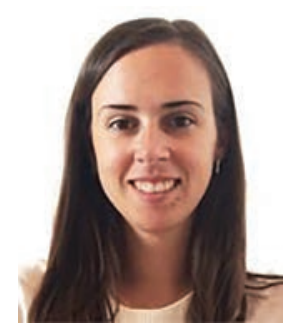

Susana Hormigos Jiménez, Graduated with honors in Architecture (Bilingual) from CEU San Pablo University. PhD Architect with Cum Laude qualification from the same university. She has developed national stays at the Technical University of Architecture of Valladolid, and an external stay at the International Center for Indoor Environment and Energy (ICIEE, Technical University of Denmark). She has worked in 'VEM Project', funded by EADS Airbus Defense \& Space and in the 'SIGLAS Project', developed at the Polytechnic University of Madrid, financed by the Ministry of Industry, Tourism and Trade. Co-author of high-impact articles and contributions to numerical simulation conferences for the analysis of fluid dynamics. Co-author of books on building facilities and technical services in buildings. She has taught since 2015 in Architecture at CEU San Pablo University in the subject of Building Facilities, also on Lighting Systems and Efficient Ventilation. Since 2018 she teaches at the University of the Balearic Islands in the subjects of Sustainability, Management and Construction of the Degree in Building. 